\title{
The Impact of COVID-19 Lockdown on Global Warming: A Call for Policy Review
}

\author{
Oluwatosin Samson Jegede $^{* *(\infty)}$, Sunday Olarewaju $\mathbf{u}^{(\mathbb{1}}$ \\ ${ }^{1}$ Department of Community Medicine, LAUTECH Teaching Hospital, Ogbomoso, Nigeria \\ ${ }^{2}$ Department of Community Medicine, University of Osun, Osogbo, Osun State, Nigeria
}

Corresponding Author: Oluwatosin Samson Jegede, MBBS, MWACP, MPH, Department of Community Medicine, LAUTECH Teaching Hospital, Ogbomoso, Nigeria. Tel: +234-8035738878, Email: dr.jegzy1@gmail.com

Received August 1, 2020; Accepted September 29, 2020; Online Published November 12, 2020

\begin{abstract}
Coronavirus disease 2019 (COVID-19) is probably the worst epidemic the world has experienced in recent times; it has led to drastic, lifesaving, and extraordinary decisions by governments of nations. Among such extraordinary measures is the closure of international borders leading to the cancellation of air travel by commercial airlines. The carbon emissions from air travel affect global warming. To this end, some authors ranked aircraft as if it were a country and compared the volume of carbon emissions generated by air travel to that generated by countries from other sources. Commercial air travel ranked seventh after Germany in terms of carbon emissions. This policy review, therefore, explored the impact of COVID-19 lockdown and travel restrictions on global warming. As a result of lockdown, there is a likelihood of a significant decrease in carbon emissions and global warming. Assuming the estimated global emissions remain constant annually, an estimated 9 gigatonnes of carbon dioxide emissions would be avoided by the end of 2020 provided that the lockdown continues. To accurately measure the value of reduced carbon dioxide emissions during the global lockdown, it is recommended that scientific studies be conducted to estimate the carbon emissions generated by the few aircraft granted waivers to transport essential commodities during the global lockdown and deduct it from the 9 gigatonnes. After the global lockdown, through a travel policy review, governments and organizations are encouraged to restrict physical meetings or activities that involve air travel only to situations where a physical presence is unavoidable.
\end{abstract}

Keywords: Air Travel, Carbon Footprint, Coronavirus, COVID-19, Global Warming, Lockdown

Citation: Jegede OS, Olarewaju S. The impact of COVID-19 lockdown on global warming: a call for policy review. Int J Travel Med Glob Health. 2021;9(2):70-72. doi:10.34172/ijtmgh.2021.11

\section{Introduction}

A new disease of the respiratory tract, coronavirus disease 2019 (COVID-19), caused by severe acute respiratory syndrome coronavirus 2 (SARS-CoV-2), a novel coronavirus, is ravaging the world causing unprecedented experiences. A large proportion of those infected with the virus usually manifests mild to moderate clinical features which recover without any medical intervention. Symptoms of COVID-19 range from anorexia, ageusia, dry cough, and excessive sneezing to fever, body aches, and persistent pain in the chest. In severe cases, COVID-19 may present with life-threatening features such as difficulty with breathing and multi-organ dysfunction. ${ }^{1}$ The elderly, and those with background medical problems such as cardiovascular diseases, diabetes mellitus, chronic respiratory diseases, and cancers are at a higher risk of developing a serious illness. ${ }^{2}$ Everyone is however susceptible, and some infected people with little or no symptoms can disseminate the infection to others. At this time, there are no specific vaccines or treatments for COVID-19; however, there are several ongoing clinical trials globally to validate potential vaccines and treatment. ${ }^{2}$

Since its outbreak, COVID-19 has shaken the world to its root. The World Health Organization (WHO) declared the outbreak a Public Health Emergency of International Concern (PHEIC) on January 30, 2020. ${ }^{3}$ Due to an increasing spread of the disease and its case-fatality rate, the WHO in its assessment, characterized COVID-19 as a pandemic on March 11, 2020. ${ }^{4}$ The disease had affected 215 countries and territories with over 5.2 million cases and over 330000 associated deaths as of May 24, 2020..$^{5}$ As countries continue to take preventive measures such as social/physical distancing, use of face mask, handwashing, and aerial fumigation, worthy of note are the extraordinary measures. Examples of such extraordinary measures to curb the spread of the disease are

Copyright $(\odot 2021$ The Author(s). This is an open-access article distributed under the terms of the Creative Commons Attribution License (http:// creativecommons.org/licenses/by/4.0), which permits unrestricted use, distribution, and reproduction in any medium, provided the original work is properly cited. 
national lockdowns and the closure of international borders leading to the grounding of both international and domestic flights. These measures have affected the global economy very deeply. ${ }^{6}$ The WHO recommended avoiding unnecessary travel and abstaining from crowded environment as ways of preventing and slowing the transmission of COVID-19. ${ }^{2}$

\section{COVID-19, Global Lockdown and Global Warming}

Beyond the importance of avoiding unnecessary travel in preventing and slowing the transmission of COVID-19, the global lockdown may be doing some good in addressing climate change. The closure of international borders and grounding of commercial airlines has increased the need for the postponement or outright cancellation of conferences and meetings forcing the scientific community to explore online alternatives. ${ }^{7}$ For example, the meeting of the $73 \mathrm{rd}$ World Health Assembly was its first-ever to be held virtually. ${ }^{3}$ Similarly, on April 1, 2020, in the face of the spreading COVID-19 pandemic, the United Nations Framework Convention on Climate Change (UNFCCC) announced that it was postponing its summit until sometime in the next year. ${ }^{8}$ Conferences and meetings have an important role in research, but they also suffer from a few disadvantages: in particular, they can be associated with a massive carbon footprint. ${ }^{7}$ The reason for this is not far-fetched; international conferences and meetings often require air travel with consequent carbon emissions and an attendant effect on global warming.

"If commercial aviation were considered a country, it would rank seventh after Germany in terms of carbon emissions". The international council on clean transportation (ICCT) stated that "unchecked, between 2016 and 2050, global aviation will generate an estimated 43 gigatonnes of carbon dioxide emissions". The contribution of air travel to climate change is widely regarded as one of the major issues threatening the existence of humans on earth. ${ }^{10}$ This contribution of the aviation industry to man-made global warming and subsequent climate change will likely triple by $2050 .{ }^{11}$ A report has identified the United States as the largest contributor to aircraft carbon emissions as the total greenhouse gas (GHG) emissions from US aircraft are seven times higher than those from China aircraft; which ranks second.

The GHG that accounts for over $60 \%$ of all GHGs is carbon dioxide $\left(\mathrm{CO}_{2}\right)^{12}$; a bye-product of aircraft carbon emissions. It is a scientific fact that the concentration of GHGs in the atmosphere co-vary with the average temperature on earth. These two closely linked atmospheric variables have continued to increase in a steady fashion since the period of the Industrial Revolution. ${ }^{12}$ As a result of global warming and climate change, several heat records continue to be broken. A report confirms that "2019 was the second warmest year on record, and 2010-2019 was the warmest decade on record ${ }^{13 \text { "; }}$ with successive decades being warmer than the preceding ones since the 1980s. ${ }^{14}$ Unattended to, the average temperature on earth is forecasted to surpass a $3^{\circ} \mathrm{C}$ rise in the 21 st century and the burden of the effect of global warming will be borne mostly by the poorest and the most vulnerable people. ${ }^{15}$

The Intergovernmental Panel on Climate Change (IPCC), in 2018, released a report detailing the impacts of global warming. The report shows that "limiting global warming to $1.5^{\circ} \mathrm{C}$ would require rapid and far-reaching transitions in land, energy, industry, buildings, transport, and cities". Reducing the carbon emissions from airplanes is an integral step to achieving the main goal of the Paris Agreement. On the occasion of the 2016 Earth Day celebration, over 170 world leaders appended their signatures to the Paris Agreement at United Nations Headquarters in New York. ${ }^{12}$ This agreement was incredibly the largest of its kind as far as the signing of an international agreement in a day is concerned. ${ }^{12}$ Similarly, the International Society of Travel Medicine (ISTM) during the CISTM16 conference in Washington DC has publicly endorsed low carbon travel to its conferences and advocated for a responsible travel among air travellers. ${ }^{10}$ Despite these laudable efforts, the international response to airplane pollution can be regarded as being inadequate. It will be impossible to tackle climate change if the international community continues to neglect airplane carbon emissions; a major source of GHGs. ${ }^{9}$ An emerging solution is the development of electric aircraft which are yet to be available for commercial use.

Arising from the total and partial lockdown in many countries, international migrations through the air have greatly been restricted to the essential ones such as transport of medical experts, food items, relief materials, medicines, and medical supplies. Internal migration through domestic flights, land transportation by cars, and heavy trucks have also been restricted. All these might have culminated in reducing carbon emissions significantly. A report from Europe states that COVID-19 lockdown has resulted in reduced nitrogen dioxide $\left(\mathrm{NO}_{2}\right)$ and $\mathrm{CO}_{2}$ emissions across Europe. ${ }^{16}$ Assuming the estimated emissions from global aviation remain constant annually, an estimated 9 gigatonnes of carbon dioxide emissions would have been avoided by the end of the year 2020, if the lockdown continues.

Conducting scientific studies is essential to estimate the quantity of carbon emission generated by essential travels (such as transportation of medical supplies and meetings of global health stakeholders) during the global lockdown. Deducting this value from the estimated 9 gigatonnes will help to accurately evaluate the effect of the COVID-19 lockdown on global warming.

On the contrary, the lockdown may also contribute to raising global temperature. For instance, with the lockdown, activities with global warming potentials have steadily increased. These include the increased use of heat-generating electrical appliances at home; aerosols from refrigerators and deep freezers; carbon emissions from generators and charcoal; and deforestation for farming purposes amongst others. The balance between the activities that may increase global warming and those that may reduce it due to COVID-19 lockdown is an ongoing discussion that needs scientific exploration to conclude on. For how long will COVID-19 lockdown continue? What happens to global warming by the time aircraft return to the sky? These are issues of central concern that may not be readily answered. However, evidence 
from the WHO indicates that the COVID-19 pandemic and lockdown might continue longer than we may ever expect.

\section{Conclusion}

The havoc which climate change has wreaked in the last decade is unprecedented; similar is the negative impact of COVID-19 on global health security. Its negative effect goes beyond physical and mental health ${ }^{17,18}$ to cut across various sectors of the economy. ${ }^{6}$ However, in an unsolicited and quiet way, the positive impact of COVID-19 on global warming might go unnoticed!

Lessons learnt from COVID-19 include the increased use of telecommuting for meetings. This has helped to limit travel by both governmental and non-governmental organisations during official duties. Post-COVID-19 lockdown, a potential way forward for heads of governments (who signed the Paris Agreement) in their resolve to address climate change, will be a review of travel policy. Governments are advised to restrict physical meetings (especially those that can generate carbon emissions) only to the situations where a physical presence is compulsory and unavoidable. This recommendation is also relevant to non-governmental organizations keeping in mind the massive carbon footprints they generate when attending conferences and meetings which can be held online. We propose advocacy by civil society organisations to drive home this recommendation.

\section{Authors' Contributions}

OSJ conceived this article. Both OSJ and OS were major contributors in writing the manuscript. Both authors read and approved the final manuscript.

\section{Conflict of Interest Disclosures}

The authors declare that they have no conflict of interest.

\section{Ethical Approval}

Not applicable.

\section{Funding/Support}

None.

\section{References}

1. Weible CM, Nohrstedt D, Cairney P, et al. COVID-19 and the policy sciences: initial reactions and perspectives. Policy Sci. 2020:1-17. doi:10.1007/s11077-020-09381-4.

2. World Health Organization (WHO). Coronavirus. WHO; 2020. Online. https://www.who.int/health-topics/ coronavirus\#tab=tab_1. Published 2020. Accessed May 23, 2020.

3. World Health Organization (WHO). Rolling Updates on Coronavirus Disease (COVID-19). WHO; 2020. https://www. who.int/Emergencies/Diseases/Novel-Coronavirus-2019/ Events-As-They-Happen. Published 2020. Accessed May 23, 2020.

4. World Health Organization (WHO). WHO Timeline COVID-19. WHO; 2020. https://www.who.int/news-room/ detail/08-04-2020-who-timeline---covid-19. Published 2020 Accessed May 23, 2020.

5. World Health Organization (WHO). Coronavirus Disease (COVID-19) Situation Report - 125. WHO; 2020. https://www.who.int/docs/default-source/coronaviruse/ situation-reports/20200524-covid-19-sitrep-125. pdf?sfvrsn=80e7d7f0_2. Accessed May 25, 2020. Published 2020.

6. Nicola M, Alsafi Z, Sohrabi C, et al. The socio-economic implications of the coronavirus pandemic (COVID-19): a review. Int J Surg. 2020;78:185-193. doi:10.1016/j.ijsu.2020.04.018.

7. Viglione G. A year without conferences? how the coronavirus pandemic could change research. Nature. 2020;579(7799):327328. doi:10.1038/d41586-020-00786-y.

8. United Nations News. Key COP26 Climate Summit Postponed to 'Safeguard Lives'. UN News; 2020. https://news.un.org/en/ story/2020/04/1060902. Accessed April 23, 2020. Published 2020.

9. Pardee V. Up in the Air: How Airplane Carbon Pollution Jeopardizes Global Climate Goals. Center for Biological Diversity; 2015. https://www.biologicaldiversity.org/programs/ climate_law_institute/transportation_and_global_warming/ airplane_emissions/pdfs/Airplane_Pollution_Report_ December2015.pdf. Published 2015.

10. Flaherty GT, Holmes A. Will flight shaming influence the future of air travel? J Travel Med. 2020;27(2). doi:10.1093/jtm/taz088.

11. Kwan I, Rutherford D, Zeinali M. U.S. Domestic Airline Fuel Efficiency Ranking, 2011-2012. Beijing: International Council on Clean Transportation (ICCT); 2014.

12. United Nations Environment Programme. Climate Change. United Nations; 2020. https://www.un.org/en/sections/issuesdepth/climate-change/. Published 2019. Accessed May 12, 2020.

13. World Meteorological Organization (WMO). WMO Confirms 2019 as Second Hottest Year on Record. WMO; 2020. https:// public.wmo.int/en/media/press-release/wmo-confirms-2019second-hottest-year-record. Published 2020. Accessed May 12, 2020.

14. UN News. Flagship UN Study Shows Accelerating Climate Change on Land, Sea and in the Atmosphere. UN News; 2020. https://news.un.org/en/story/2020/03/1059061.

15. United Nations Sustainable Development. Take Urgent Action to Combat Climate Change and its Impacts. United Nations; 2016. https://www.un.org/sustainabledevelopment/climatechange/\%0Ahttp://www.un.org/sustainabledevelopment/ climate-change-2/. Published 2016.

16. Wilks J, Ging JP. Coronavirus and Climate: How Much Impact is the Current Lockdown Really Having on Our Environment? Euronews; 2020. https://www.euronews.com/2020/04/13/ covid-19-and-climate-how-much-impact-is-the-currentlockdown-really-having-on-our-environm. Accessed May 23, 2020. Published 2020.

17. Serafini G, Parmigiani B, Amerio A, Aguglia A, Sher L, Amore M. The psychological impact of COVID-19 on the mental health in the general population. QJM. 2020;113(8):531-537. doi:10.1093/qjmed/hcaa201.

18. Pfefferbaum B, North CS. Mental Health and the Covid-19 Pandemic. N Engl J Med. 2020;383(6):510-512. doi:10.1056/ NEJMp2008017. 